\title{
ACERVOS DOS ARQUIVOS INSTITUCIONAIS DO CENTRO DE MEMÓRIA DA EDUCAÇÃO DA FACULDADE DE EDUCAÇÃO/USP
}

\author{
Carmen Sylvia Vidigal Moraes \\ CME/FEUSP \\ carmensvmoraes@gmail.com
}

\section{- Centro Regional de Pesquisas Educacionais Prof. Queiroz Filho/CRPE- 1956}

As fotografias aqui apresentadas integram o conjunto documental do Centro Regional de Pesquisas Educacionais Prof. Queiroz Filho/CRPE, um dos arquivos institucionais pertencentes ao Acervo do Centro de Memória da Educação da Faculdade de Educação da Universidade de São Paulo/ CME-FEUSP.

$\mathrm{O}$ arquivo compõe-se de documentos e fotografias acumulados no decorrer das atividades científicas, pedagógicas e administrativas do Centro Regional de Pesquisas Educacionais de São Paulo, desde sua fundação por Lei Federal, em 1956, até a extinção por Decreto lei, durante a ditadura civil militar, em 1975. Recebeu dois nomes ao longo de sua existência: CRPE Prof. Queiroz Filho e CRPE do Sudeste.

A organização do Centro Brasileiro de Pesquisas Educacionais (CBPE) e dos Centros Regionais de Pesquisas Educacionais (CRPEs), dentro da estrutura já existente do Instituto Nacional de Estudos Pedagógicos (INEP), órgão subordinado ao então Ministério da Educação e Cultura e sob a direção de Anísio Teixeira, representou importante estímulo ao desenvolvimento de pesquisas em ciências sociais sobre questões relacionadas à educação brasileira, seja por meio da contratação de pesquisadores formados nessa área do conhecimento para integrar seus quadros permanentes, seja pelo financiamento a projetos em ciências sociais elaborados fora dessas instituições (FERREIRA, 2008). Como tem indicado a literatura educacional, os Centros de Pesquisas Educacionais do INEP foram parte integrante de um movimento mais amplo de intensificação da ação governamental no sentido da construção de aparatos oficiais destinados a subsidiar as políticas públicas por meio do estudo e do planejamento no campo educacional. Esses centros promoveram a realização de pesquisas no Distrito Federal e nos estados de São Paulo, Minas Gerais, Pernambuco, Bahia e Rio Grande do Sul. Pelas pesquisas desenvolvidas, sobretudo entre os anos de 1956 e 1961, os centros do INEP e sua Revista "Educação e Ciências Sociais" obtiveram a colaboração de um diversificado grupo de cientistas sociais que sugeriram interpretações, algumas vezes inovadoras, sobre as relações entre a educação escolarizada e as mudanças sociais que se processavam, em diferentes ritmos, nas diversas regiões brasileiras naquele momento 
histórico (XAVIER, 1999).

A "ideia força” que levou à criação dos Centros Brasileiro e Regionais de Pesquisas Educacionais enfatizava o tratamento das questões educacionais de um ponto de vista técnico profissional e a preservação dos documentos históricos e da recuperação de documentos relevantes no campo da educação. Como afirma Xavier (1999), seu caráter de instituição de pesquisas e de assessoramento técnico, bem como sua vinculação à Unesco (com o fornecimento de recursos financeiros) contribuíram para que o CBPE desenvolvesse relação de relativa autonomia com o poder do Estado. De acordo com a autora, pode-se afirmar que tal experiência institucional "viabilizou-se em meio às estratégias de valorização do campo pedagógico e como parte do programa de cientificação das profissões moderna”. Ao mesmo tempo em que propunha a centralidade da educação como objeto de pesquisa no campo das ciências sociais, os Centros de Pesquisas Educacionais desenvolveram "amplo programa de profissionalização de quadros da educação, tanto no que concerne à preparação de pesquisadores como na formação e especialização de professores para atuarem no sistema público de ensino" (XAVIER, 1999, p. 104).

Entre as principais razões do afastamento da sociologia em relação à educação, Luiz Antônio Cunha (1992) refere-se à demolição do CBPE pelo governo militar, às condições políticas de controle ideológico que se sucederam e, principalmente, à orientação da Reforma Universitária de 1968 que promoveu a fragmentação das Faculdades de Filosofia, Ciências e Letras no país e a consequente segregação da pedagogia em relação às outras disciplinas.

\section{O Centro Regional de Pesquisas Educacionais de São Paulo/CRPE-SP}

Instalado em prédio originalmente destinado pelo MEC a um Centro Regional de Aperfeiçoamento do Magistério, o CRPE/SP teve Fernando de Azevedo como seu primeiro diretor. O novo órgão acompanhava os objetivos fixados para o Centro Brasileiro: a. pesquisa das condições culturais e escolares e das tendências de desenvolvimento de cada região e da sociedade brasileira como um todo, para o efeito de conseguir-se a elaboração gradual de uma política educacional para o país; b. elaboração de planos, recomendações e sugestões para a revisão e a reconstrução educacional do país em cada região nos níveis primário, médio, e superior e no setor de educação de adultos; c. elaboração de livros de fontes e de textos, preparo de material de ensino, estudos especiais sobre administração escolar, currículos, psicologia educacional, medidas escolares, formação de mestres e sobre quaisquer outros temas que concorram para o aperfeiçoamento do magistério nacional; d. treinamento e 
aperfeiçoamento de administradores escolares, orientadores educacionais, especialistas de educação e professores de escolas normais e primárias.

Em 1958, é instituída a Escola Experimental com o objetivo de realizar ensaios de técnicas de ensino, bem como oferecer cursos de aperfeiçoamento para professores, inclusive de outros países, por meio de convênio estabelecido com a UNESCO.

O conjunto documental do Centro Regional de Pesquisa Educacional, composto por cerca de 3.000 documentos, possui 894 fontes textuais: relatórios de atividades, monografias de final de cursos da Divisão de Aperfeiçoamento e Magistério/DAM e outras fontes representativas das ações desenvolvidas nos seus diferentes setores: Divisão de Estudos e Pesquisas Educacionais/Depes, Serviço de Recursos Audiovisuais/SRAV, Serviços Administrativos/SA, Serviço de Estatística/SE, Serviço de Documentação/SD. O arquivo é também constituído por 355 imagens ampliadas, 461 fichas, com provas contato, e 1920 negativos relacionados a eventos, aulas e espaços internos da instituição. Entre outras preciosidades, o acervo contém a série Carlos Mascaro (CM), um dos diretores do CRPESP, composta pelos dossiês Anísio Teixeira, Fernando de Azevedo, Lourenço Filho, Murilo Braga, Laerte Ramos de Carvalho. O cadastramento das informações básicas em base de dados está em fase de construção e quase concluído.

As fotografias, em grande parte, dizem respeito às atividades do Serviço de Recursos Audiovisuais, aos encontros nacionais e internacionais de professores, às aulas de classes experimentais, entre outras. 
Foto 1: Alunos da Escola Experimental e Professor Celso Ferretti em aula com utilização de equipamento de áudio/Serviço de Recursos Audiovisuais do Centro Regional de Pesquisas

Educacionais/CRPESP. Ano 1958-9.

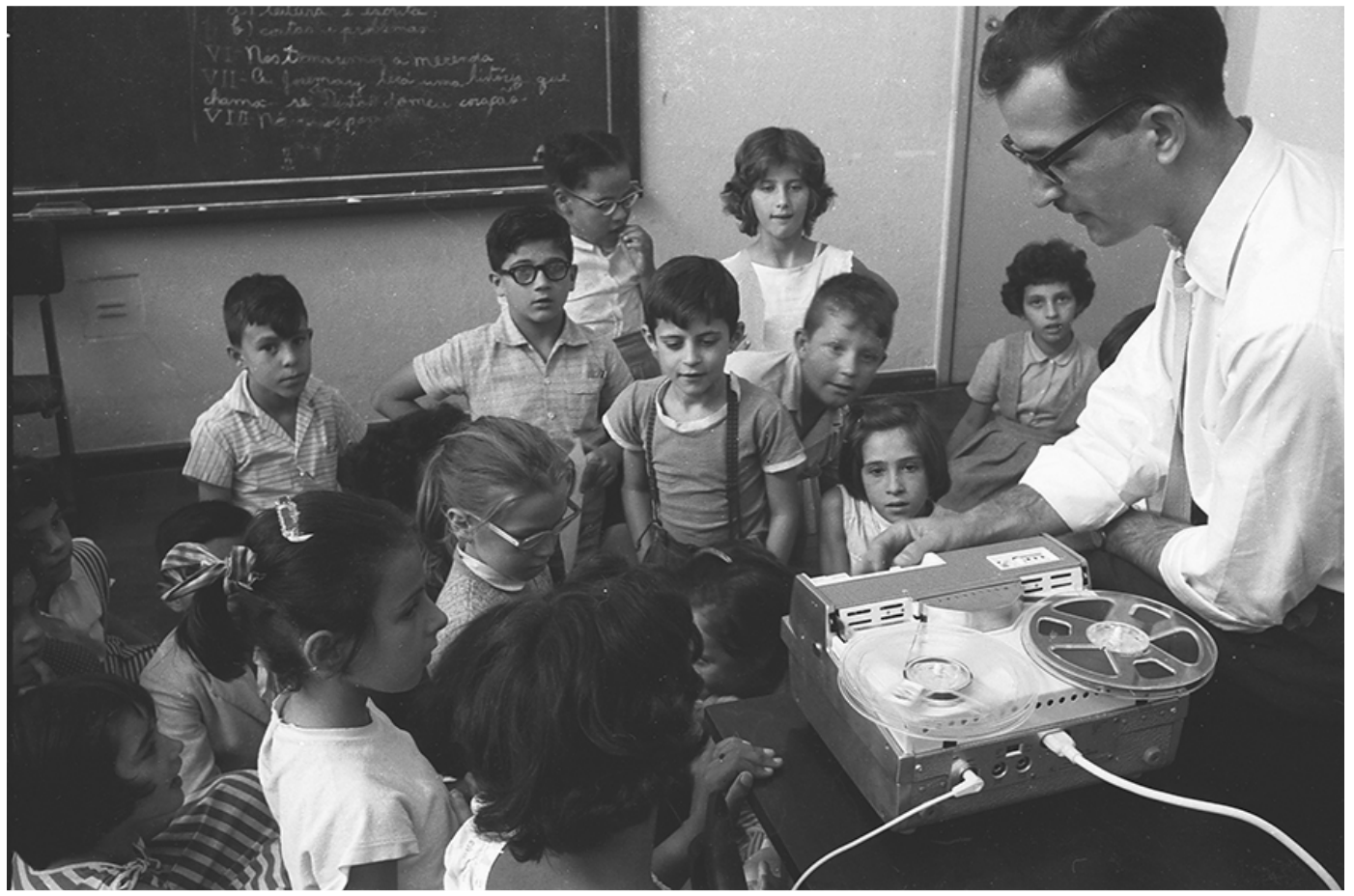

Fonte: Arquivo CRPESP - CMEFEUSP.

Foto 2: Fachada do prédio do Centro Regional de Pesquisas Educacionais de São Paulo CRPESP, na Faculdade de Educação da Universidade de São Paulo/FEUSP, Cidade Universitária. Ano - 1970.

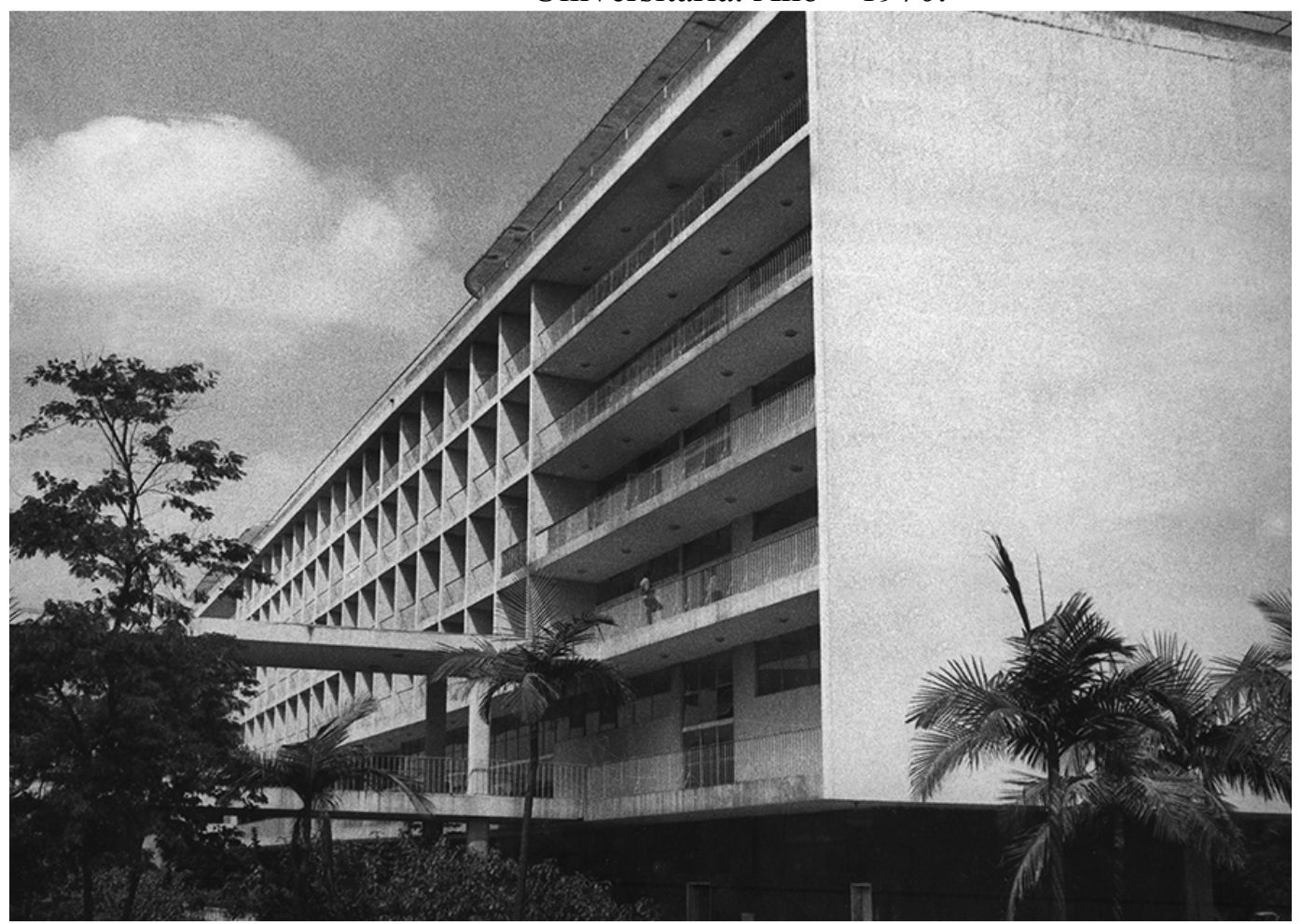

Fonte: Arquivo CRPESP - CMEFEUSP. 


\section{REFERÊNCIAS}

CUNHA, Luiz Antônio. A Educação na Sociologia: um objeto de estudo rejeitado? In: Cadernos CEDES. Sociologia e Educação: diálogo ou ruptura? São Paulo: Papirus, 1992.

FERREIRA, Márcia Santos. Os Centros de Pesquisas Educacionais do INEP e os estudos em ciências sociais sobre a educação no Brasil. Revista Brasileira de Educação, v. 13, n. 38, p. 279-411, maio/ago. 2008.

XAVIER, Libânia Nacif. O Brasil como Laborátorio; Educação e Ciências Sociais no Projeto dos Centros Brasileiros de Pesquisas Educacionais - CBPE/INEP/MEC (1950-1960). Bragança Paulista: IFAN/CDAPH/EDUSF, 1999, 281 p. 